\title{
How much Carbohydradte?
}

Dear Sir,

At the end of his editorial (Diabetologia 19, 409) Dr. Reaven states that he believes that recommendations leading to major modifications in the kind and amount of carbohydrate and fat in the diabetic diet must be based upon sound experimental data. Earlier he states that be believes (my italics) that IDD should consume a diet containing $15-20 \%$ of daily calories as protein, with the remainder divided equally between fat (low in saturated fat) and carbohydrate. Incidentally, if fat is to be $>40 \%$ of daily calories and low in saturated fat, the diet must perforce contain more than usual of unsaturated fats. That is Dr. Reaven's belief. Where is the 'sound experimental data' to support it? The question is rhetorical: I know the answer. There isn't any. In fact there is no experimental evidence of the long-term clinical trial variety, with morbidity/mortality end points, to support any dietary policy in diabetics. There is, however, circumstantial evidence from epidemiological studies which is consistent with the hypothesis that a high (complex) carbohydrate/low fat diet protects against coronary heart disease in diabetics. This is evident from the comparison of Japanese diabetics in Hawaii and Japan, respectively [1].

Coronary heart disease incidence is substantially higher in Hawaii; serum cholesterol and triglyceride levels are also higher and fat comprises a larger, with carbohydrate a lower, proportion of the total caloric intake. In the WHO Study [2] the prevalence of major Q-wave abnormalities was substantially lower in diabetics in Tokyo and Hong Kong, two populations which, like most of the world's diabetics (and non-diabetics) consume a high carbohydrate/low fat diet.

It may be too much to expect, or even hope, that starting a high carbohydrate/low fat diet at ages $40+$ will make much impact upon coronary heart disease. However, in young onset diabetics the possibility of preventing atherosclerosis, or slowing its progression, is much greater. Of course, we don't have definitive proof that such diets will have the desired effect and, given the complexities and cost of organising an appropriate trial, I don't suppose we ever shall. Nevertheless, I believe the circumstantial evidence is sufficient to warrant this dietary policy and I know of no evidence that it may cause harm. If Dr. Reaven thinks it does, then would he counsel Asian diabetologists to recommend to their patients that they reduce their carbohydrate calories and increase those from fat?

Microvascular disease is another story and there is no good evidence that dietary habits in different population groups influence its frequency or severity. There is reasonably good evidence to the contrary [3].

Yours faithfully,

\section{R. J. Jarrett}

\section{References}

1. Kawate R, Yamakido M, Nishimato Y, Bennett PH, Hamman RF, Knowler WC (1979) Diabetes mellitus and its vascular complications in Japanese migrants on the Island of Hawaii. Diabetes Care 2: 161-170

2. Keen H, Jarrett RJ (1979) The WHO Multinational Study of Vascular Disease in Diabetes: 2. Macrovascular Disease Prevalence. Diabetes Care 2: 187-195

3. Jarrett RJ, Keen H (1979) The WHO Multinational Study of Vascular Disease in Diabetes: 3. Microvascular Disease. Diabetes Care 2: 196-201

Dr. R. J. Jarrett

Department of Community Medicine

Guy's Hospital Medical School

London Bridge SE1 9RT

England
Dear Sir,

Professor Reaven makes a strong case against recommending to diabetics an increase in dietary carbohydrate [1] as has been suggested by the American Diabetes Association's Committee on Food and Nutrition [2]. He offers three main reasons:

Firstly, a high carbohydrate diet might be translated into an increased intake of simple sugars and Professor Reaven fears a situation where " $42 \%$ of total daily calories are ingested as Danish pastry". Our three experimental high carbohydrate diet studies which have suggested a beneficial effect in insulin dependent and non-insulin dependent diabetics have used carbohydrates derived from cereal, vegetable and leguminous sources $[3,4,5]$. These are the kinds of carbohydrate we would recommend. In addition to being high in carbohydrate the diets have contained large amounts of dietary fibre and very little simple sugar. On the basis of existing data, it is impossible to disentangle to what extent the beneficial effect is derived from the carbohydrate per se and to what extent from dietary fibre but no discussion concerning the carbohydrate content of the diabetic diet should disregard the likely beneficial effect of fibre. Most protagonists of a diet fairly high in carbohydrate, including ourselves, have not recommended a diet high in simple sugars and the fact that some people will break the rules is surely not a reason to exclude those who will obey them from a diet which may be more beneficial.

Secondly, Professor Reaven is concerned about the effects of a high carbohydrate diet in untreated or badly controlled diabetics. We agree entirely that there is no convincing evidence concerning this group of patients. A small number of our patients, all over 50 years, not obese and inadequately controlled (appreciable glycosuria and random blood glucoses around $10 \mathrm{mmol} / \mathrm{l}$ ) on maximal doses of oral hypoglycaemic agents have shown appreciable improvement on a high carbohydrate diet but a formal study is necessary before making firm recommendations for this group of patients.

Finally he expresses concern about the possible hypertriglyceridaemic effect of a high carbohydrate diet. In our three studies 
carried out in both insulin dependent and non-insulin dependent patients, triglycerides (both when measured fasting and at regular intervals during the day and night) have been similar on high and low carbohydrate diets. In fact two markedly hypertriglyceridaemic individuals showed an appreciable fall in triglycerides on the high-carbohydrate-high-fibre diets. Detailed triglyceride results are given in the most recent paper [5].

We agree with Professor Reaven that diets in which as much as $60 \%$ of total energy is provided by carbohydrate (such as our own) may not be acceptable to many diabetics and we are presently studying the effects of varying quantities and types of carbohydrate and fibre. However, other studies [6] as well as our own convince us that restriction of carbohydrate to only $40 \%$ of total daily energy may well prevent many diabetics from achieving a more satisfactory degree of metabolic control. At the time of writing, Professor Reaven had available only our data relating to noninsulin dependent patients [3]; we wonder whether the most recent papers concerning insulin dependent patients $[4,5]$ as well as another published sometime ago [7] might influence his judgement against increasing the carbohydrate. For the present we would recommend that for the majority of insulin dependent and noninsulin dependent diabetics, the diet could safely contain $55 \%$ of carbohydrate calories (a level acceptable to most people) provided that it was high in dietary fibre and low in simple sugars. Attention to energy balance must of course remain as a prime consideration in all diabetics.

\section{J. I. Mann, H. C. R. Simpson, and T. D. R. Hockaday}

\section{References}

1. Reaven GM (1980) How high the carbohydrate? Diabetologia 19: $409-413$

2. Committee of the American Diabetes Association on Food and Nutrition (1979) Special report - principles of nutrition and dietary recommendations for individuals with diabetes mellitus. Diabetes Care 2: $520-523$

3. Simpson RW, Mann JI, Eaton J, Moore RA, Carter R, Hockaday TDR (1979) Improved glucose control in maturity onset diabetes treated with high carbohydrate-modified fat diet. $\mathrm{Br}$ Med J I: 1753-1756

4. Simpson RW, Mann JI, Eaton J (1979) High-carbohydrate diets and insulin dependent diabetics. Br Med J II: 523-525

5. Simpson HCR, Simpson RW, Lousley S, Carter RD, Geekie M, Hockaday TDR, Mann JI (1981) A high carbohydrate leguminous fibre diet improves all aspects of diabetic control. Lancet I: 1-5

6. Mann JI (1979) Diet and diabetes. Diabetologia 18: 89-95

7. Hockaday TDR, Hockaday JM, Mann JI, Turner RC (1978) A prospective comparison of modified fat-high carbohydrate with standard low-carbohydrate dietary advice in the treatment of diabetes: a one year follow-up study. Br J Nutr 39: 357-362

\section{Dr. J. I. Mann}

University of Oxford

Department of Community Medicine and General Pratice

8 Keble Road

Oxford OX1 $3 Q \mathrm{~N}$

England

\section{Dear Sir:}

One is almost reluctant to undertake the discussion of a complex subject within the space limitations of an Editorial. On the other hand, doubts you may have about accepting the challenge are overcome by the certain knowledge that your colleagues will call to your attention any mistakes and/or ambiguities in your point of view. This generalization clearly applies to my recent comments in Diabetologia (19: 409, 1980), and the letters of Dr. Jarrett and of Dr. Mann and his colleagues have raised important questions. I am delighted to have the opportunity to respond to them, and I hope that in the process my own stance may be clarified.

Dr. Jarrett makes three major points. The first is that the incidence of coronary heart disease in diabetics is substantially lower in populations who consume a high carbohydrate/low fat diet, and that it is this difference in dietary habits which accounts for the difference in coronary heart disease. I am delighted with this conclusion. As one who is primarily interested in lipoprotein metabolism, I am pleased to realize that an epidemiologist with an international reputation has decided that my area of research interest is of such crucial importance in determining incidence of heart disease in diabetics. On the other hand, I am a little surprised that Dr. Jarrett does not consider the possibility that other factors known to predispose to heart disease might be playing a role in this situation. Is it at least possible that the differences in incidence of heart disease in the various populations might be due to causes other than the diet? For example, the incidence of coronary heart disease in Pima Indians, $45 \%$ of whom had diabetes, was about onehalf that of the predominantly white and non-diabetic population of Tecumseh, Michigan [1]. Given Dr. Jarrett's view as to the crucial role of diet as a cause of coronary heart disease in diabetics,
I anticipated that the Pima Indians must eat a high carbohydrate/ low fat diet as compared with the inhabitants of Tecumseh. However, that does not seem to be the case, and "the two most widely used foods in the Pima diet are beans (generally pinto) and tortillas; the latter are made from wheat, flour, lard, salt and water. They are either baked on an ungreased grill or deep fat-fried [2]." It does not sound like a diet which is particularly high in carbohydrate and low in fat. Indeed, the Pima diet was estimated to consist (as percentage of total calories) of approximately $12 \%$ protein, $44 \%$ carbohydrate, and $44 \%$ fat, figures which are essentially identical to that of the United States general population. The polyunsaturated/saturated fat ratio was also similar in the two groups, and the only real difference seemed to be that the proportion of carbohydrate derived from sucrose was significantly less in the Pima's diet. On the basis of these observations I would submit that there must be a number of variables which can lead to a different incidence of coronary heart disease in various populations of diabetics, and I do not feel compelled to accept the notion that protection from this complication is derived from consuming a high carbohydrate/low fat diet.

A second issue raised by Dr. Jarrett is that (if I may paraphrase his comments) it would be a shame not to try and prevent the development and/or progression of atherosclerosis in young onset diabetics by denying them the benefit of a high carbohydrate/low fat diet. Unfortunately, one man's benefit may be another man's poison. I can remember when it was considered inappropriate to withhold corticoid therapy for young patients with idiopathic nephrotic syndrome. In retrospect, it seems likely that this was not the best approach. I realize it is dangerous to argue from analogy, but I would submit that there is at least a possibility that high carbohydrate diets can lead to deleterious metabolic effects in pa- 
tients with diabetes, and some of these were discussed in detail in the initial Editorial.

Finally, Dr. Jarrett wonders if I would "counsel Asian diabetologists to recommend to their patients that they reduce their carbohydrate calories and increase those from fat?" That certainly was not my intent. Indeed, what I suggested was that "recommendations leading to major modifications in the kind of carbohydrate and fat in the diabetic diet must be based upon sound experimental data." Most members of the Western world eat a diet similar to the one I advised for patients with diabetes, and I tried to suggest that we should not drastically change conventional eating patterns until we have more information. It follows, therefore, that I would not recommend that Asians change their life style. By the same token, I hesitate to recommend that diabetics in Palo Alto switch to a high carbohydrate/low fat diet.

The issues raised by Dr. Mann and associates are equally important. Dr. Mann begins by pointing out that I fear a situation where " $42 \%$ of total daily calories are ingested as Danish pastry." I can only assume that the casual reader wondered about the mystical significance of $42 \%$ of daily calories and why I picked an Danish pastry. If the original quote had been provided in its totality, there might have been less confusion. Furthermore, I think it would have put into very sharp focus the basic difference between my view point and that expressed by Dr. Mann and colleagues. What I did say was the following: "it is possible that a high carbohydrate diet for many patients will be translated into increased intake of simple sugars, and I am afraid that encouraging patients to eat a high carbohydrate diet can lead to a situation in which $42 \%$ of total daily calories are ingested as Danish pastry, not as wholemeal bread. Under these circumstances I am not sure that the effect would be as beneficial as the result of Simpson et al." The reference to wholemeal bread is a function of the fact that the high carbohydrate diet studied by Simpson and colleagues [3] actually contained $42 \%$ of total calories as wholemeal bread. The diet had additional interesting characteristics. For example, the diet permitted patients to eat $1 \mathrm{oz}$ of meat at each of the three main meals of the day, with the remainder of the calories consisting of skimmed milk, margarine, fruit and vegetables. The question I raised in my Editorial related to the possibility that such a diet could reach wide acceptability. I am concerned that large numbers of patients would not be compliant with such a diet for very long, and Dr. Mann and his colleagues are clearly of a different opinion. I do not think that arguments as to taste are likely to be very rewarding, and I would suggest that interested readers come to their own conclusions by looking at the composition of the high carbohydrate/modified fat diet described in the publication of Simpson et al. [3].

A second major point revolves around our differing points of view as to the potential harm that may result from eating a high carbohydrate diet in terms of elevation of plasma triglyceride levels. Dr. Mann and colleagues point out that this did not happen when patients consume a high carbohydrate/high fibre diet [3]. That indeed seems to be the case, at least when one is eating a diet as rigid as that porposed by Mann and colleagues. Indeed, similar findings have been pointed out by Anderson et al. [4]. Thus, plasma triglyceride levels did not increase when patients were switched from a control diet containing (as percentage total calories) $18 \%$ protein, $43 \%$ carbohydrate and $39 \%$ fat to a high carbohydrate/high fibre diet containing similar amounts of protein and $70 \%$ carbohydrate and $12 \%$ fat. No sucrose was added to the diets, and the patients eating the high carbohydrate/high fibre diet were allowed on some days to eat as much as $1 \mathrm{oz}$ of turkey and 1 oz of roast beef. The rest of their caloric intake composed primarily of leguminous vegetables and fruits. For example, one evening meal consisted of whole wheat bread, baked potato, lima beans, canned beets, canned asparagus and banana. Again, interested readers can consult the paper in question to review the specifics of the diet, and come to their own conclusions as to its palatability, acceptability, and the possibility of long term compliance. Anderson and colleagues also indicated that a high carbohydrate diet, in the absence of high fibre, led to a significant increase in plasma triglyceride concentration. I certainly have no disagreement with the argument that very special high carbohydrate/high fibre diets can results, at least in some patients, in a modest decrease in ambient plasma glucose concentration, without any appreciable change in triglyceride concentration. However, the real question is how many patients can follow these diets, and what is the likelihood that the current enthusiasm for high carbohydrate diets will lead to substitution of more conventional kinds of dietary carbohydrate, which are not high in fibre. It seems to me that the major benefit of the high carbohydrate diets that have been used to date is a function of their very high fibre on content. For example, I know of no study of the effect of average carbohydrate/high natural fibre diets on various aspects of metabolic control in diabetics.

Finally, it is only fair to point out that there are also enthusiasts for a low carbohydrate diet in the treatment of diabetes. For example, there are at least three papers [5-7] which suggest that low carbohydrate diets can also result in striking improvement of diabetic control. Unfortunately, these studies are complicated by the fact that weight loss also occurred, and it is difficult to be entirely sure as to which of these factors was most responsible for the improvement. However, the conclusion reached in all three papers was that one could not account for the observed changes on the basis of weight loss alone.

In conclusion, $I$ think that the issue of diabetic diet remains an important one, and $\mathrm{I}$ appreciate the opportunity to respond to the very thoughtful criticisms of my Editorial voiced by Drs. Jarrett and Mann and his colleagues. If this exchange stimulates the initiation of new studies, it will have been more than worth the effort.

Sincerely yours,

\section{Gerald M. Reaven}

\section{References}

1. Ingelfinger JA, Bennett PH, Liebow IM, Miller M (1976) Coronary heart disease in the Pima Indians; Electrocardiographic findings and postmortem evidence of myocardial infarction in a population with a high prevalence of diabetes mellitus. Diabetes 25: 561-565

2. Reid JM, Fullmer SD, Pettigrew KD, Burch TA, Bennett PH, Miller M, Whedon GD (1971) Nutrient intake of Pima Indian women: relationships to diabetes mellitus and gallbladder disease. Am J Clin Nutr 24: 1281-1289

3. Simpson RW, Mann JI, Eaton J, Moore RA, Carter R, Hockaday TDR (1979) Improved glucose control in maturity-onset diabetes treated with high-carbohydrate-modified fat diet. $\mathrm{Br}$ Med J I: $1753-1756$

4. Anderson JW, Chen W-JL, Sieling B (1980) Hypolipidemic effects of high-carbohydrate, high-fiber diets. Metabolism 29: 551-558

5. Rudnick PA, Taylor KW (1965) Effect of prolonged carbohydrate restriction on serum-insulin levels in mild diabetes. $\mathrm{Br}$ Med J I: $1225-1228$

6. Wall JR, Pyke DA, Oakley WG (1973) Effect of carbohydrate restriction in obese diabetics: relationship of control to weight loss. Br Med J I: 557-578

7. Perkins JR, West TET, Sonksen PH, Lowy C, Iles C (1977) The effects of energy and carbohydrate restriction in patients with chronic diabetes mellitus. Diabetologia 13: 607-614

Gerald M. Reaven, M. D.

Geriatric Research, Education and Clinical Center

Veterans Administration Medical Center

3801 Miranda Avenue

Palo Alto, CA 94304

USA 